\title{
O USO DE RESÍDUOS DA CONSTRUÇÃO CIVIL COMO AGREGADOS NA PRODUÇÃO DE CONCRETO
}

\author{
Emília Xavier do Rêgo Barros \\ Escola Politécnica de Pernambuco \\ Universidade de Pernambuco \\ 50.720-001 - Recife, Brasil \\ emiliaxrb@hotmail.com.com
}

\author{
Stela Fucale \\ Escola Politécnica de Pernambuco \\ Universidade de Pernambuco \\ 50.720-001 - Recife, Brasil \\ sfucale@upe.poli.br
}

Resumo A construção civil é o setor que mais cresce em nosso país, gerando novos empregos, e, contudo também, uma problemática, os entulhos. Estes, muitas vezes, são depositados irregularmente na malha urbana. Uma forma de evitar tal degradação das áreas e tamanho desperdício de materiais consiste na prática da reciclagem. Este trabalho apresenta um estudo de viabilidade técnica do uso de agregados de resíduos da construção civil (RCC) para a produção de concretos sem função estrutural, de acordo com a NBR 15116 (ABNT, 2004). O RCC estudado nessa pesquisa foi coletado em uma obra localizada em Recife, Pernambuco, em fase de alvenaria. A metodologia consistiu inicialmente em beneficiamento da amostra de resíduo coletada para transformação em agregado miúdo reciclado. Os ensaios laboratoriais de caracterização física e mecânica (composição gravimétrica, granulometria, teor de materiais pulverulentos, absorção de água, índice de vazios, massa unitária, massa específica, módulo de finura, abatimento, resistência à compressão simples e à compressão diametral) foram realizados de acordo com as normas técnicas da ABNT. A análise da composição gravimétrica da amostra de RCC indicou que $54,9 \%$ do material era constituído de tijolos cerâmicos e argamassa, enquanto que $27,64 \%$ da amostra era constituída de material miúdo. O ensaio de material pulverulento reafirmou a grande quantidade de material miúdo no RCC, $12,47 \%$, e o ensaio de absorção de água evidenciou a presença dos tijolos cerâmicos, visto que o RCC apresentou uma absorção de 10,01\%. Foi adotada uma mesma relação água/cimento para todas as famílias de concreto, convencional, $50 \%$ e $100 \%$ de substituição de agregado miúdo natural pelo reciclado no estado seco ou úmido. Os ensaios de resistência à compressão axial e diametral realizados nos concretos endurecidos apresentaram resultados melhores para o concreto da família com $100 \%$ de substituição do agregado miúdo natural pelo reciclado seco do que o concreto da família convencional. Conclui-se, portanto, que apesar das suas propriedades físicas desfavoráveis para dosagens de concreto, o agregado miúdo reciclado atingiu os critérios exigidos pela NBR 15116 (ABNT, 2004), além do concreto confeccionado com 100\% de substituição do agregado miúdo natural pelo reciclado seco apresentar resistência mecânica maior com o aumento dos dias de cura; possibilitando, assim, a utilização de agregados miúdos provenientes de resíduos da construção civil em fase de alvenaria para a produção de concretos sem função estrutural. 


\section{Introdução}

A Indústria da Construção Civil vem crescendo bastante no Brasil, assim como em Recife, sendo responsáveis pela geração de empregos, pela movimentação financeira e pelo crescimento do país. Contudo, surgem diversas problemáticas ao lado deste súbito crescimento, como o aumento da exploração dos recursos naturais do nosso planeta na utilização destes como matéria-prima e a geração de resíduos.

Os resíduos de construção e demolição (RCD), segundo Angulo (2005) representam 50\% da massa dos resíduos sólidos urbanos. Na cidade do Recife, a geração de resíduos provenientes da construção civil alcança um montante superior a 20.000 toneladas/mês (dados atuais da Prefeitura do Recife), e estima-se que gera-se de 2000 a 3000 toneladas/dia de RCC em Recife (Prefeitura do Recife/2012). Havendo, desta forma, uma necessidade de controlar os impactos ambientais gerados pelos entulhos da construção civil. Para Angulo (2000), a reciclagem tem surgido como uma forma de amenizar a ação nociva dos resíduos no ambiente urbano, gerando ainda novos produtos comercializáveis.

A importância do gerenciamento destes resíduos no Brasil é abordada na Resolução do Conselho Nacional do Meio Ambiente (CONAMA) no 307 do ano de 2002, que visa reduzir, reutilizar ou reciclar resíduos por meio de diretrizes, critérios e procedimentos para a gestão dos resíduos da construção civil. Na cidade do Recife, existe uma lei, $\mathrm{n}^{\mathrm{o}}$ 17.072/2005, que cria o Programa de Gerenciamento de Resíduos da Construção Civil, que proíbe a disposição ilegal dos resíduos, regulamenta o seu transporte e a sua destinação obedecendo ao estabelecido na referida resolução do CONAMA.

Desta forma, essa pesquisa visa a reutilização dos resíduos de uma construção civil coletado na cidade do Recife, de forma a impulsionar a reciclagem e uma possível conscientização ambiental e sustentável; e a utilização destes no próprio canteiro de obras como agregados miúdos na produção de concretos sem função estrutural. Em outras palavras, esta pesquisa tem como objetivo geral o estudo da viabilidade técnica do uso de agregados miúdos reciclados de RCC gerados na fase de alvenaria de uma obra da cidade do Recife, para produção de concreto.

\section{Contextualização}

Um dos grandes problemas discutidos na atualidade é a geração de resíduos pela indústria da construção civil, segundo Buttler (2003).
Os resíduos podem ser gerados tanto na fase de construção, nos canteiros de obras, quanto nas reformas, manutenções e demolições. Na etapa de construção os resíduos são gerados, em sua grande maioria, pela aplicação de técnicas rudimentares que ocasionam o desperdício de materiais e na incompatibilidade de projetos, enquanto que, as demolições geram grande parte dos resíduos por serem realizadas sem processos racionalizados e sem nenhum tipo de segregação (Gusmão et al, 2008). O gerenciamento destes é de extrema importância, visto que, reduzir as perdas de materiais é extremamente desejável no ponto de vista econômico e ambiental.

\subsection{Os impactos da geração de RCC}

O grande problema da geração de resíduos é o seu mau gerenciamento, ou na maioria dos casos a ausência deste, e ainda o elevado desperdício de materiais. Destaca-se que, muitas vezes, estes resíduos são despejados irregularmente ou clandestinamente, o que pode gerar problemas de contaminação no solo e na água subterrânea, além disto, a atividade da construção civil consome recursos naturais, que por fim gerará mais resíduos devido ao desperdício em obras de construção civil. A Figura 01 ilustra exemplo de disposição ilegal de RCC.

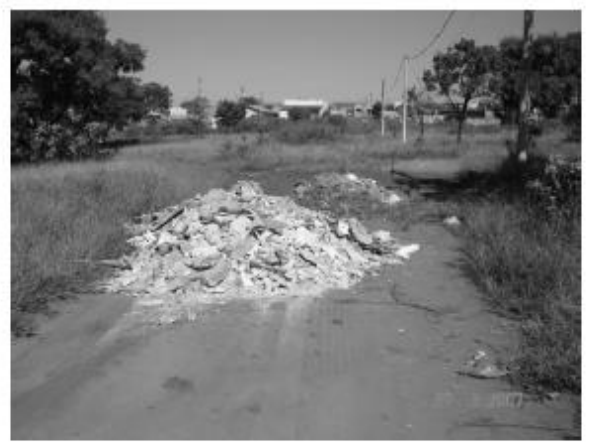

Figura 01: Disposição ilegal de RCC (Fonte: FREITAS, 2009).

Para Lima (1999), a prática da reciclagem dos resíduos de construção é uma das alternativas para lidar com os impactos que os mesmos causam.

\subsection{A reciclagem dos resíduos da construção civil}

Apesar de o Brasil dispor de uma grande quantidade de recursos naturais, estes são esgotáveis, e já se pode observar a escassez de algumas matérias-primas em algumas cidades, como Recife, por exemplo, onde a areia utilizada para concreto vem de municípios localizados a mais de 70 km de distância (GUSMÃO et al, 2008). 
A reciclagem e/ou reutilização dos resíduos da construção é uma alternativa sustentável para diminuir a exploração do meio ambiente e uma maneira de solucionar os impactos ambientais que os resíduos da construção civil proporcionam, já que os mesmos terão uma finalidade.

Diversas pesquisas tentam viabilizar a reciclagem de entulhos de obras para seu uso como agregado, já que a utilização de agregados reciclados diminui a exploração de recursos naturais, o impacto destes quando são despejados em depósitos inadequados e o custo do seu gerenciamento, transporte e multas por despejo inadequado (RODRIGUES, 2011).

\section{Metodologia}

\subsection{Coleta de amostras}

A amostra de RCC investigada nesta pesquisa fo icoletada em uma obra de um edifício multifamiliar na região Metropolitana do Recife/PE, que encontrava-se em fase de alvenaria. A obra possuía estrutura de concreto armado, alvenaria de bloco cerâmico e revestimento interno (argamassa, gesso).

\subsection{Composição Gravimétrica}

É de fundamental importância conhecer a natureza dos resíduos investigados, que servirão como constituintes na confecção do concreto. Desta forma, a finalidade da composição gravimétrica é fornecer esta informação do agregado utilizado, por meio do qual é possível determinar sua natureza a partir de uma separação visual de acordo com o tipo de material constituinte (material miúdo, material cerâmico, argamassa, concreto, misto e outros) e com uma posterior pesagem dos mesmos.

\subsection{Benefícios do RCC}

Os materiais cerâmicos, a argamassa, o concreto e os materiais mistos (diferentes materiais unidos), constituintes do resíduo bruto, foram separados visualmente e reduzidos de tamanho por meio de britador de mandíbulas.

Juntamente com o material beneficiado pelo britador, o material miúdo do RCC coletado e utilizado nesta pesquisa foi peneirado em uma peneira de abertura 2,36 $\mathrm{mm}$ para ser utilizado como agregado miúdo. $\mathrm{O}$ peneiramento pela malha de 2,36 $\mathrm{mm}$ foi necessário para fins de comparação com o agregado miúdo de RCC da pesquisa de Rodrigues (2011) e também, para ser similar ao agregado miúdo natural (areia) quanto à granulometria. Satisfazendo, dessa forma, a norma NBR 7211 (ABNT, 2005) que considera agregado miúdo todo material que passa pela peneira com abertura de malha $4,75 \mathrm{~mm}$.

\subsection{Ensaios laboratoriais}

Em laboratório, realizou-se os ensaios de caracterização do RCC (granulometria, absorção de água, teor de materiais pulverulentos, massa específica, massa unitária e volume de vazios) e ensaios de resistência mecânica nos concretos confeccionados, conforme a Associação Brasileira de Normas Técnicas: Determinação da composição granulométrica - NBR NM 248/2003; Determinação da absorção de água - NBR NM 30/2003; Determinação do material fino que passa através da peneira de $75 \mu \mathrm{m}$, por lavagem - NBR NM 46/2003; Determinação da massa específica de agregados miúdos por meio do frasco de Chapman - NBR 9976/1987; - Determinação da massa unitária e do volume de vazios - NBR NM 30/2001; Determinação da consistência pelo abatimento do tronco de cone - NBR NM 67/1998; Ensaio de compressão de corpos-de-prova cilíndricos - NBR 5739/2007; Determinação da resistência à tração por compressão diametral de corpos-de-prova cilíndricos - NBR 7222/1994.

\subsection{Dosagem experimental}

Como a resistência e a durabilidade do concreto dependem da proporção entre os seus materiais constituintes, foi executado um traço teste para obter um único traço viável para as substituições de $0 \%, 50 \%$ e $100 \%$ de agregado miúdo reciclado. $\mathrm{O}$ traço teste 1,0:2,0:3,3 (cimento: agregado miúdo: agregado graúdo), com relação água/cimento igual a 0,60 ; possibilitou observar o comportamento do agregado miúdo na mistura, que mostrou a necessidade da adição de maior conteúdo de água, mudando a relação água/cimento para 0,75 ; já que usualmente os constituintes de RCC (argamassa, cerâmica, concreto, dentre outros) apresenta maior absorção que agregados naturais.

A execução do traço teste foi essencial para encontrar um traço trabalhável tanto para a substituição de $0 \%, 50 \%$ e $100 \%$ do agregado miúdo natural pelo agregado miúdo reciclado de RCC seco ou pré-umedecido. Assim, nesta pesquisa foram aplicados dois traços, já que utiliza-se o RCC seco e pré-umedecido a fim de avaliar o agregado reciclado mediante a relação água/cimento sem e com uma prévia absorção de água. A tabela 01 detalha os traços calculados.

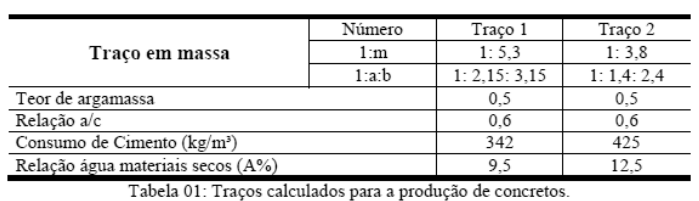


A partir da execução dos traços e do teor de substituição, $0 \%, 50 \%$ ou $100 \%$, as famílias de concreto foram nomeadas de acordo com a tabela 02 .

\begin{tabular}{c|c|c|c}
\hline \multicolumn{4}{c}{ PRODUÇ̃̃o DO CONCRETO } \\
\hline Familia & Substituição & Traço & T.U.V. \\
\hline CREs & $0 \%$ & Traço 1 & $1,00: 2,15: 3,15: 0,60$ \\
\hline $\mathbf{R u}_{\mathbf{u} 50}$ & $50 \%$ RCC úmido & Traço 1 & $1,00: 2,15: 3,15: 0,60$ \\
\hline $\mathbf{R} \mathbf{5 0}$ & $50 \%$ RCC seco & Traço 2 & $1,00: 1,40: 2,40: 0,60$ \\
\hline $\mathbf{R u 1 0 0}$ & $100 \%$ RCC úmido & Traço 1 & $1,00: 2,15: 3,15: 0,60$ \\
\hline Rs $\mathbf{1 0 0}$ & $100 \%$ RCC seco & Traço 2 & $1,00: 1,40: 2,40: 0,60$ \\
\hline
\end{tabular}

Foram moldados um total de $60 \mathrm{CP}$ 's de dimensões 10 x $20 \mathrm{~cm}$, conforme a norma NBR 5738 (ABNT, 2008), 12 para cada família, sendo 02 para o ensaio de resistência à compressão axial e 01 para o ensaio de resistência diametral, cujas idades de cura consideradas fora 3,7,14 e 28 dias.

\section{Resultados}

\subsection{Composição Gravimétrica}

A pesagem dos constituintes do RCC coletado possibilitou a suas respectivas porcentagens em massa, que podem ser verificadas na figura 02 .

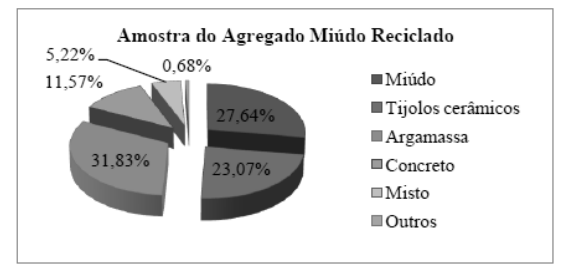

Figura 02: Composição Gravimétrica do RCC coletado.

Observa-se a predominância de três constituintes, material miúdo $(27,64 \%)$, tijolos cerâmicos $(23,07 \%)$ e argamassa $(31,83 \%)$, que juntos predominam $82,54 \%$ do RCC coletado, evidenciando materiais típicos que são gerados em obra de construção civil em fase de alvenaria.

\subsection{Granulometria}

A realização do ensaio permitiu a construção da curva granulométrica do RCC (Figura 03), que foi comparada com os limites da distribuição granulométrica de agregado miúdo para concreto, impostos pela NBR 7211 (ABNT, 2009).

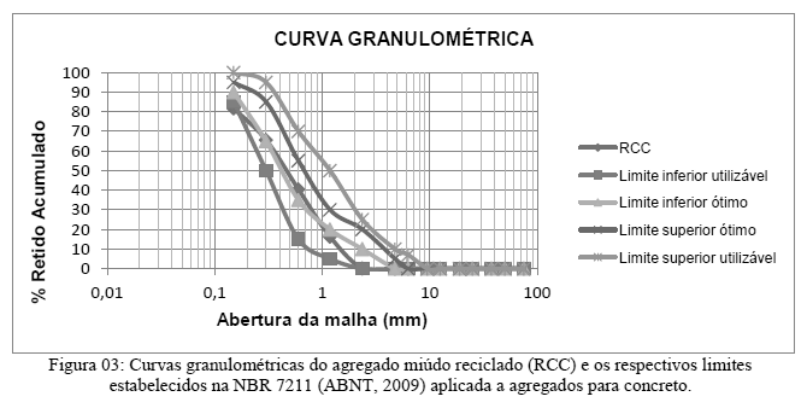

Analisando as curvas, pode-se perceber que o RCC está entre os limites utilizáveis estabelecidos pela referida Norma, ultrapassando somente, um pouco o limite inferior utilizável.

\subsection{Teor de materiais pulverolentos}

$\mathrm{O}$ agregado miúdo reciclado apresentou um teor de material pulverulento de $12,47 \%$, estando dentro do limite estabelecido pela norma de agregados reciclados de resíduos sólidos da construção civil (ABNT NBR 15116/2004), não ultrapassando $20 \%$, e não satisfazendo o limite estabelecido pela norma de agregados para concreto (ABNT NBR $7211 / 2009$ ), que estabelece que o teor de material pulverulento devem ser de $3 \%$ para concreto submetido ao desgaste superficial e $5 \%$ para concretos protegidos do desgaste superficial.

\subsection{Absorção de água}

Segundo Lima (1999), uma das características que mais difere o agregado reciclado do natural (convencional) é na absorção de água. Por isto, a absorção de água dos agregados reciclados é muito importante quando se estuda o seu uso em concreto, visto que, a taxa de absorção dos agregados interfere diretamente na relação água/cimento do traço, conforme Leite (2001).

Após 24h imerso em água, o agregado miúdo reciclado (RCC) apresentou absorção de água igual a 10,0\%, enquanto que o agregado miúdo natural apresentou absorção de água igual a $0,2 \%$. Esta elevada absorção do RCC também foi encontrado em outros estudos. Rodrigues (2011) encontrou $10,28 \%$ de absorção de água, enquanto Lovato (2007) encontrou valores para cada resíduo estudado, variando entre $6 \%$ a $11,7 \%$.

\subsection{Massa específica, massa unitária e vo- lume de vazios}

A tabela 03 sintetiza os resultados encontrados na realização dos ensaios. 


\begin{tabular}{c|c}
\hline \multicolumn{1}{c|}{\begin{tabular}{c} 
Ensaios Realizados \\
\cline { 2 - 2 } $\begin{array}{l}\text { Massa Especifica }\left(\mathbf{g} / \mathrm{cm}^{3}\right) \\
\text { (NBR NM 52/2009) }\end{array}$
\end{tabular}} & $\begin{array}{c}\text { Resultados } \\
\text { obtidos }\end{array}$ \\
\hline $\begin{array}{l}\text { Massa Unit. Agregado Solto }\left(\mathbf{k g} / \mathbf{d m}^{3}\right) \\
\text { (NBR NM 45/2006) }\end{array}$ & $\mathbf{2 , 4 8}$ \\
\hline $\begin{array}{l}\text { Massa Unit. Agregado (SSS) }\left(\mathbf{k g} / \mathbf{d m}^{3}\right) \\
\text { (NBR NM 45/2006) }\end{array}$ & $\mathbf{1 , 4 2}$ \\
\hline $\begin{array}{l}\text { Volume de Vazios (\%) } \\
\text { Tabela 03: Resultados de massa especifica, massa unitária e volume de vazios do agregado miúdo } \\
\text { reciclado (RCC). }\end{array}$
\end{tabular}

De acordo com Lima (1999), pelo fato de os resíduos da construção serem compostos de materiais porosos, os agregados reciclados provenientes deles apresentam, na maioria das vezes, massas específicas e unitárias menores que os agregados naturais. Tal fato aconteceu nesta pesquisa, na de Angulo (1998), Carneiro (2005), Lovato (2007) e Rodrigues (2011).

Outro índice que indica a grande porosidade do agregado miúdo reciclado é o volume de vazios, que representa mais da metade, exatamente $58,8 \%$, do espaço entre os grãos da massa de agregado. $\mathrm{O}$ que pode ter ocasionado a presença de vazios nos corpos-de-prova com $100 \%$ de substituição do agregado miúdo natural pelo reciclado.

\subsection{Abatimento}

Nesta pesquisa não houve a fixação do abatimento a fim de analisar o comportamento do agregado reciclado seco e com pré-umedecimento na mistura do traço. A tabela 04 apresenta os resultados do abatimento de tronco de cone, também chamado de teste Slump, realizado durante a fase de dosagem de cada família de concreto produzida.

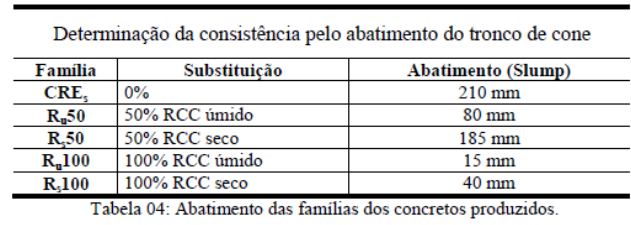

Os concretos com $0 \%$ de agregado miúdo reciclado apresentaram o maior valor de abatimento, $210 \mathrm{~mm}$, enquanto que os concretos com $100 \%$ de agregado miúdo apresentaram os menores valores, com abatimento de 40 $\mathrm{mm}$.

\subsection{Resistência à Compressão Axial}

Este ensaio foi realizado em todas as famílias de concreto confeccionadas, nas idades de 3, 7, 14 e 28 dias, cujos resultados são apresentados na tabela 05 .

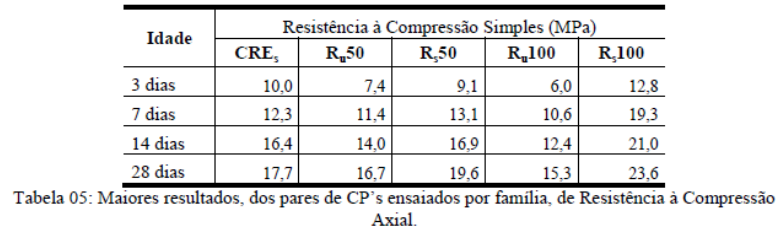

Todas as famílias obtiveram uma resistência à compressão crescente com os dias de cura. A família Rs100, com $100 \%$ de substituição de RCC sem seco, obteve resultados maiores que o concreto convencional (CREs) desde a primeira idade até a última. Os concretos sem prévia adição de água demonstrou melhoria de resistência com o acréscimo do teor de agregado reciclado. Já os concretos confeccionados com agregados miúdos reciclados com pré-umedecimento não obtiveram resultados melhores que o convencional e que os confeccionados com agregado miúdo reciclado seco. A explicação para isto pode ser que a água adicional do pré-umedecimento aumentou a relação água/cimento, o que acarretou em uma baixa resistência.

\subsection{Resistência à compressão Diametral}

Este ensaio também foi realizado em todas as famílias de concreto confeccionadas, nas idades de 3, 7, 14 e 28 dias, os resultados são apresentados na tabela 06 .

\begin{tabular}{l|r|r|r|r|r}
\hline \multirow{2}{*}{ Idade } & \multicolumn{5}{|c}{ Resistência à Compressão Diametral (kgf) } \\
\cline { 2 - 6 } & $\mathbf{C R E}_{\mathbf{5}}$ & $\mathbf{R}_{\mathbf{u}} \mathbf{5 0}$ & \multicolumn{1}{c}{$\mathbf{R}_{\mathbf{s}} \mathbf{5 0}$} & \multicolumn{1}{c}{$\mathbf{R}_{\mathbf{u}} \mathbf{1 0 0}$} & \multicolumn{1}{c}{$\mathbf{R}_{\mathbf{s}} \mathbf{1 0 0}$} \\
\hline 3 dias & 4207 & 3050 & 2755 & 3586 & 5247 \\
\hline 7 dias & 5232 & 3931 & 4815 & 4398 & 7041 \\
\hline 14 dias & 7319 & 6044 & 6620 & 5206 & 8646 \\
\hline 28 dias & 3297 & 7371 & 6418 & 5886 & 8605 \\
\hline
\end{tabular}

De 03 dias a 28 dias de idade, a família Ru50 apresentou um aumento de $141,67 \%$ em sua resistência, enquanto a Rs50 apresentou um aumento de $132,96 \%$. Já a família Ru100 o aumento foi de $64,14 \%$ e a Rs 100 de $64 \%$. Apesar do pequeno decréscimo da família Rs 100 na resistência das idades 14 e 28 dias, a mesma apresentou o maior resultado, com uma resistência à tração igual a 8646 kgf em 14 dias de cura, com uma variação de resistência igual a 1,18 em relação ao concreto de referência (CREs) aos 14 dias. Logo, pode-se afirmar que, o aumento do teor de agregado reciclado de RCC acarretou em um aumento no parâmetro de resistência à compressão diametral, para o caso da família sem prévio umedecimento.

No último dia de cura (28 dias), o concreto convencional (CREs) apresentou resistência diametral inferior ao seu primeiro dia de cura (3 dias) porque houve um problema na prensa do ensaio que não direcionou a força, o que acarretou nessa baixa resistência. Porém, com exceção do Rs100, o concreto convencional foi superior a todos os 
outros nesta análise do parâmetro de resistência à compressão diametral.

\section{Considerações Finais}

Embora os agregados miúdos reciclados provenientes de RCC serem mais heterogêneos que o agregado miúdo natural e terem apresentado maior absorção, propriedades características importantes para a utilização em dosagens de concreto, esta pesquisa apresentou a viabilidade da sua utilização na confecção de concretos sem função estrutural. Visto que, o concreto produzido $100 \%$ com agregado miúdo reciclado seco apresentou uma resistência à compressão axial, 33,3\%, e uma resistência à compressão diametral, 18,1\%, maiores que o concreto convencional. $\mathrm{O}$ concreto produzido $50 \%$ com agregado miúdo reciclado seco apresentou uma resistência à compressão axial superior $10,7 \%$ e uma resistência à compressão diametral inferior $9,55 \%$ do concreto convencional. Os concretos produzidos com agregado miúdo reciclado previamente umedecido apresentaram resultados inferiores ao convencional, mas não tão distintos; o com 50\% de substituição foi inferior 5,64\% em sua resistência à compressão axial e $17,4 \%$ em sua resistência à compressão diametral, enquanto o com $100 \%$ de substituição apresentou uma resistência à compressão axial inferior $13,5 \%$ e uma resistência à compressão diametral inferior $28,9 \%$.

Portanto, esse estudo apresenta uma possibilidade de aproveitamento do Resíduo da Construção Civil (RCC), diminuindo assim a quantidade de resíduos despejados em locais inapropriados, e encontrando uma alternativa sustentável para a diminuição da exploração de recursos naturais pela indústria da construção civil.

\section{Referências}

[1] ABNT - Associação Brasileira de Normas Técnicas. NBR 15.116, Agregados reciclados de resíduos sólidos da construção civil - Utilização em pavimentação e preparo de concreto sem função estrutural - Requisitos. Rio de Janeiro, 2004.

. NBR NM 248, Agregados - Determinação da composição granulométrica. Rio de Janeiro, 2003.

[3]

NBR NM 46, Agregados - Determinação do material fino que passa através da peneira de $75 \mu \mathrm{m}$, por lavagem. Rio de Janeiro, 2003.

NBR NM 45, Agregados - Determinação da massa unitária e do volume de vazios. Rio de Janeiro, 2006.
NBR NM 30, Agregado miúdo - Determinação da absorção de água. Rio de Janeiro, 2001.

[6] _. NBR 9775, Agregados - Determinação da Massa Específica de Agregados Miúdos por meio do Frasco de Chapman. Rio de Janeiro, 1987.

[7] _ NBR NM 67, Concreto - Determinação da consistência pelo abatimento do tronco de cone. Rio de Janeiro, 1998.

[8] . NBR 7222, Argamassa e Concreto - Determinação da resistência à tração por compressão diametral de corpos-de-prova cilíndricos.

[9] _. NBR 5739, Concreto - Ensaio de compressão de corpos-de-prova cilíndricos. Rio de Janeiro, 2007.

[10] . NBR 7211, Agregados para concreto - Especificação. Rio de Janeiro, 2005.

[11] . NBR 5738, Concreto - Procedimento para moldagem e cura de corpos-de-prova.

[12] Angulo, S.C. Variabilidade de Agregados Graúdos de Resíduos de Construção e Demolição Reciclados. Dissertação de Mestrado - Escola Politécnica de São Paulo, Universidade de São Paulo, São Paulo, 2000.

[13] Angulo, S.C. Caracterização de Agregados de Resíduos de Construção e Demolição Reciclados e a Influência de suas Características no Comportamento de Concretos. Dissertação de Doutorado - Escola Politécnica de São Paulo, Universidade de São Paulo, São Paulo, 2005

[14] Buttler, A.M. Concreto com Agregados Graúdos Reciclados de Concreto - Influência da Idade de Reciclagem nas Propriedades dos Agregados e Concretos Reciclados. Dissertação de Mestrado Escola de Engenharia de São Carlos, Universidade de São Paulo, São Carlos, 2003.

[15] Carneiro, F.P. Diagnósticos e Ações da Atual Situação dos Resíduos de Construção e Demolição na Cidade do Recife. Dissertação de Mestrado - Universidade Federal da Paraíba, João Pessoa, 2005.

[16] CONAMA - Conselho Nacional De Meio Ambiente. Resolução no 307. Brasília, 2002.

[17] Freitas, I.M. Os Resíduos de Construção Civil no Município de Araraquara/SP. Dissertação de Mestrado - Centro Universitário de Araraquara, UNIARA, Araraquara, 2009.

[18] Gusmão, A.D. Manual de Gestão dos Resíduos da 
Construção Civil. Camaragibe, PE, Gráfica Editora, 2008.

[19] Leite, M.B. Avaliação de Propriedades Mecânicas de Concretos Produzidos com Agregados Reciclados de Resíduos de Construção e Demolição. Dissertação de Doutorado - Universidade Federal do Rio Grande do Sul, Porto Alegre, 2001.

[20] Lima, J.A.R. Proposição de Diretrizes para Produção e Normalização de Resíduo de Construção Reciclado e de suas Aplicações em Argamassas e Concretos. Dissertação de Mestrado Escola de Engenharia de São Carlos, Universidade de São Paulo, São Paulo, 1999.

[21] Lovato, P.S. Verificação dos Parâmetros de Controle de Agregados Reciclados de Resíduos de Construção e Demolição para Utilização em Concreto. Dissertação de Mestrado - Universidade Federal do Rio Grande do Sul, Porto Alegre, 2007.

[22] Prefeitura do Recife. Lei no 17072. Recife, 2005.

[23] Prefeitura do Recife. Empresa de Manutenção e Limpeza Urbana - EMLURB, Projetos e Ações, Coleta de Resíduos da Construção Civil. Disponível em: http://www.recife.pe.gov.br/pr/servicospublicos/emlurb/civil.php

[24] Rodrigues, C.R. de S. Avaliação de Propriedades Mecânicas de Concretos Produzidos com Agregado Miúdo Reciclado de Resíduo da Construção Civil. Dissertação de Mestrado - Escola Politécnica de Pernambuco, Universidade de Pernambuco, Recife, 2011. 